\title{
PENGEMBANGAN MODEL PEMBELAJARAN MELOMPAT MELALUI PERMAINAN LOMPAT CERMIN UNTUK SISWA SEKOLAH DASAR
}

\author{
Faizal Suharnoko ${ }^{1}$ dan Guntur Firmansyah ${ }^{2}$ \\ ${ }^{1}$ SDN Lumbangrejo 1 Prigen Pasuruan \\ ${ }^{2}$ IKIP Budi Utomo Malang \\ E-mail: ichalfaizal17@gmail.com ${ }^{1}$,gunturpepeng@gmail.com²
}

Diterima: 3 Juli 2018; Lolos: 22 September 2018; Dipublikasikan: 14 Oktober 2018

DOI: https://doi.org/10.29407/js_unpgri.v4i2.12169

\begin{abstract}
Abstrak
Penelitian bertujuan untuk mengembangkan model pembelajaran gerak dasar melompat yang menarik dan variatif yaitu melalui permainan lompat cermin yang sesuai dengan dengan karakteristik gerak dasar melompat yang mengacu pada teknik pelaksanaan dan prinsip-prinsipnya. Berdasarkan data awal yang diperoleh melalui pengamatan menunjukkan bahwa perlu adanya dilakukan penelitian lebih mendalam. Penelitian pengembangan model pembelajaran ini mengikuti langkah-langkah yang digunakan oleh Gall \& Borg II yang dikutip oleh Ramadan yang dimodifikasi oleh peneliti karena pertimbangan waktu dan biaya. Secara ringkas data yang diperoleh dari evaluasi ahli pembelajaran diperoleh hasil $81,25 \%$ pada kategori baik, evaluasi ahli pendidikan jasmani diperoleh hasil $91,67 \%$ pada kategori baik, evaluasi ahli permainan lompat cermin diperoleh hasil $87,50 \%$ pada kategori baik, uji coba kelompok kecil diperoleh data 69,27 \% pada kategori cukup, uji coba kelompok besar diperoleh data 82,29 \% pada kategori baik maka dapat disimpulkan bahwa model pembelajaran hasil pengembangan dapat digunakan.
\end{abstract}

Kata kunci: Pengembangan, model pembelajaran, lompat cermin, sekolah dasar.

\section{DEVELOPMENT OF LEARNING MODELS THROUGH MIRROR JUMP GAMES FOR ELEMENTARY SCHOOL STUDENTS}

\begin{abstract}
The study aims to develop a model of basic motion learning that is interesting and varied, namely through the mirror jump game which is in accordance with the basic motion characteristics of jump which refers to the implementation technique and its principles. Based on the initial data obtained through observations, it is necessary to conduct more in-depth research. Research into the development of this learning model follows the steps used by Gall \& Borg II cited by Ramadan modified by researchers because of time and cost considerations. In summary, the data obtained from the evaluation of learning experts obtained results of 81 , $25 \%$ in the good category, physical education expert evaluation obtained $91.67 \%$ in the good category, expert evaluation of mirror jumping games obtained $87.50 \%$ in the good category, trial small groups obtained $69.27 \%$ data in the sufficient category, large group trials obtained $82.29 \%$ data in the good category it can be concluded that the development learning model can be used
\end{abstract}

Keywords: Development, learning model, mirror jump, elementary school.

Email : gunturpepeng@gmail.com

No Handphone : 085646543122
(C) 2018 UN PGRI Kediri

p-ISSN: $2548-7833$

e-ISSN: 2477-3379 


\section{PENDAHULUAN}

Pembelajaran olahraga di sekolah diharapkan dapat memberikan dampak positif pada pertumbuhan dan perkembangan anak sehingga inovasi dan pengembangan harus terus dilakukan. Penggunaan model pembelajaran dan media pembelajaran yang menarik, bervariasi, aman serta mudah digunakan merupakan senjata utama yang harus dimiliki oleh setiap pengajar. Penguasaan gerak bukan satu-satunya tujuan yang harus dicapai pada proses pembelajaran olahraga disekolah akan tetapi kematangan emosional, psikis, sosial juga harus menjadi target dari hasil pembelajaran olahraga. Meskipun hasil dari banyak penelitian yang dilakukan di bidang pendidikan jasmani menunjukkan bahwa kurikulum pendidikan jasmani tidak ada pada tingkat yang tepat dan memuaskan (Ljubojevi, Muratovi, \& Bubanja, 2016)

Anni yang dikutip Kisyanto (2015) menjelaskan bahwa belajar merupakan suatu proses penting bagi perubahan perilaku setiap orang dan belajar itu mencakup segala sesuatu yang dipikirkan dan dikerjakan oleh seseorang. Prinsip belajar menurut teori belajar tertentu, teori tingkah laku dan prinsip-prinsip pengajaran dalam implementasinya akan berintegrasi menjadi prinsip-prinsip pembelajaran. Menurut Burstiando \& Nurkholis (2018) menyatakan bahwa dalam kegiatan belajar pembelajaran disekolah siswa dibekali berbagai macam hal mulai dari pembelajaran yang bersifat kognitif, afektif maupun psikomotor. Ketiga ranah tersebut menjadi indikator tercapainya tujuan pembelajaran. Seringkali dalam mencapai tujuan pembelajaran, guru mengemas materi pembelajaran dalam bentuk permainan, hal itu dikarenakan dengan anak cenderung senang bermain sambil belajar.

Game atau permainan merupakan suatu sistem yang memiliki aturan-aturan tertentu dimana pemain akan terlibat di dalam suatu permasalahan sehingga dapat menghasilkan suatu hasil yang dapat diukur yaitu menang dan kalah. Permainan merupakan sesuatu hal yang dimainkan dengan suatu aturan tertentu yang biasa digunakan untuk tujuan kesenangan dan dapat juga untuk tujuan pendidikan (Adhanisa, 
Kridalukmana, \& Martono, 2016). Sesuai dengan hasil penelitian BOTA (2103) bahwa permainan dinamis mempunyai hubungan yang positif dengan pertumbuhan anak, perkembangan anak, keterampilan gerak, dan keharmonisan hubungan sosial antar teman.

Lompat dan loncat adalah suatu rangkaian gerakan untuk mengangkat tubuh ke atas melalui beberapa proses yaitu lari, tumpuan, melayang dan mendarat (Ariawan, 2015). Gerak dasar lompat merupakan gerak dasar lokomotor yang perlu dikembangkan pada usia anak sekolah dasar atau usia 6-8 tahun. Gerak dasar lokomotor merupakan dasar dari macam-macam keterampilan yang sangat perlu adanya bimbingan, latihan dan pengembangan agar anak-anak dapat melaksanakan dengan benar (Ardhika, 2012).

Gerak lokomotor mempunyai peran penting dalam pembelajaran pendidikan jasmani, terutama cabang olahraga yang menuntut perpindahan tempat atau titik berat badan seperti lari cepat, lompat jauh, lompat tinggi dan cabang olahraga lainnya. Para siswa sekolah dasar seringkali mengalami hambatan atau kesulitan dalam mengikuti pembelajaran pendidikan jasmani yang menuntut kemampuan gerak lokomotor (Hanief \& Sugito, 2015).

Lompat dan loncat merupakan salah satu dari gerak motorik anak yang harus terus mendapatkan perhatian untuk terus ditingkatkan sesuai dengan program yang dilakukan secara teratur. Hasil penelitian keterampilan motorik anak pada usia sebelum sekolah dasar dapat meningkat melalui beberapa modifikasi permainan seperti berjalan dengan pergeseran, lompatan lateral diatas tali, tekuk dibangku dan berdiri lompat jauh (Stanojević, 20116).

Beberapa penelitian tindakan kelas yang menggunakan berbagai model permainan lompat yang mendapatkan hasil positif atau sumbangan kepada prestasi melompat anak-anak diantaranya permainan rangkaian 3 pos (Bakhtiar, 2010), modifikasi permainan engklek (Ardhika, 2012), modifikasi permainan lompat karet (Pramono, Setyawati, \& Akhiruyanto, 2015), permainan jump box (Ali Khafidin S, 2015), permainan lompat 
kangguru (Suroso, 2015), permainan lompat gelang-gelang (Raharjo, 2015). Serta penelitian-penelitian eksperimen yang membuktikan bahwa permainan melompat berpengaruh pada prestasi lompat dan pertumbuhan motorik anak seperti penelitian yang dilakukan oleh (Ilham, 2011) dan (A. Suroso, Rustiana, \& Sugiharto, 2013).

Hasil obervasi awal melalui metode pengamatan yang dilakukan peneliti terhadap pembelajaran gerak dasar melompat di SDN Lumbangrejo 02 dan SDN Pecalukan 01 diperoleh data bahwa: 1) Pembelajaran gerak dasar melompat belum berjalan dengan maksimal, 2) Hampir sebagian besar siswa merasa kurang percaya diri melakukan gerakan melompat, 3) Media pembelajaran yang digunakan oleh guru adalah yang sesungguhnya sehingga kurang variatif, 4) Sarana dan prasarana sekolah yang memadai untuk mengembangkan model pembelajaran gerak dasar melompat.

Berdasarkan latar belakang diatas peneliti berusaha mengembangkan model pembelajaran gerak dasar melompat yang menarik dan variatif yaitu melalui permainan lompat cermin yang sesuai dengan dengan karakteristik gerak dasar melompat yang mengacu pada teknik pelaksanaan dan prinsip-prinsipnya. Diharapkan dengan adanya pengembangan ini bisa dijadikan sebagai media untuk mengembangkan kemampuan gerak dasar siswa sekolah dasar. Lebih jauh lagi model pembelajajaran yang dikembangkan menjadi bahan dan media alternatif untuk memberikan materi pembelajaran gerak dasar melompat.

\section{METODE}

Model pengembangan yang digunakan mengikuti langkah-langkah Research \& Development $(R \& D)$ dari Gall \& Borg (2007) yang dikutip Ramadan (2018) secara lengkap terdiri dari sepuluh langkah pelaksanaan strategi penelitian dan pengembangan, yang dimodifikasi oleh peneliti sehingga menjadi delapan langkah karena berbagai pertimbangan. Subjek penelitian melibatkan 38 siswa kelas 5 laki-laki dan perempuan yang berusia 11-12 tahun. Uraian langkah dalam penelitian sebagai berikut: 


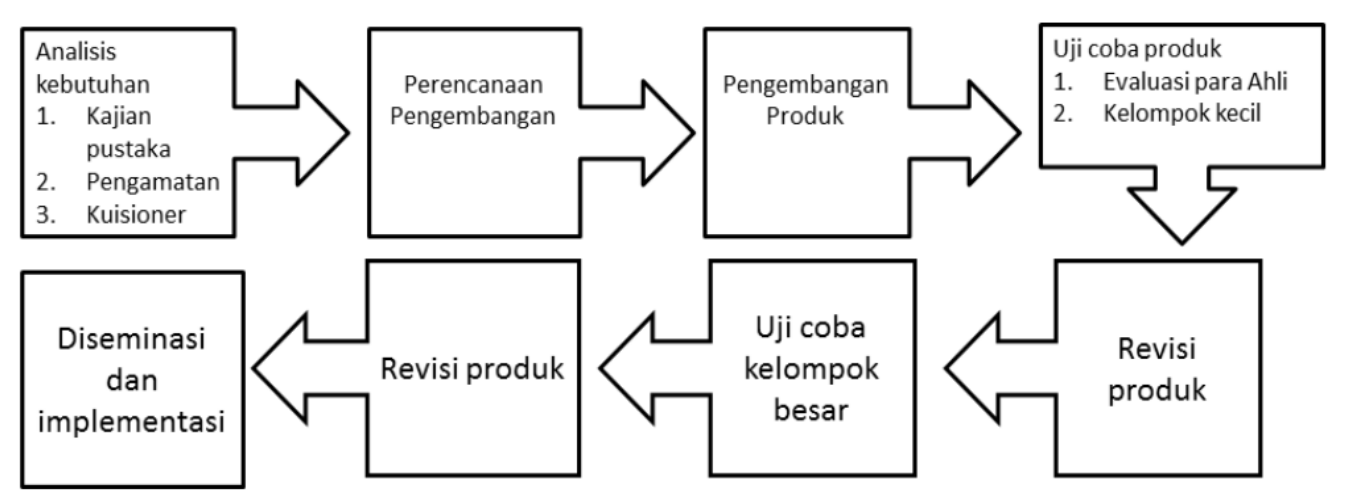

Bagan 1. Prosedur Pengembangan Gall \& Borg yang dimodifikasi

1. Analisis kebutuhan (need assessment), melalui penyebaran angket pada 2 guru penjas dan 30 siswa SDN Lumbangrejo 02 dan SDN Pecalukan 01 Prigen Pasuruan sesuai dengan langkah pertama Gall \& Borg.

2. Perencanaan pembuatan produk model pembelajaran gerak dasar melompat melalui permainan lompat cermin untuk siswa sekolah dasar sesuai dengan langkah kedua Gall \& Borg.

3. Pengembangan produk awal yang didasarkan dari hasil analisis kebutuhan.

4. Uji coba produk awal yang sudah terbentuk dijustifikasi oleh terhadap 1 orang ahi pembelajaran, 1 orang ahli pendidikan jasmani dan 1 orang ahli permainan lompat cermin. Selanjutnya, produk yang telah dijustifikasi oleh para ahli diuji cobakan pada siswa SDN Lumbangrejo 02 dan SDN Pecalukan 01 Prigen Pasuruan dengan melibatkan 8 subyek uji coba sesuai dengan langkah keempat Gall \& Borg.

5. Merevisi hasil uji coba dan memperbaiki atau menyempurnakan hasil uji coba sesuai dengan hasil dari uji coba tahap I (kelompok kecil) sesuai dengan langkah kelima Gall \& Borg.

6. Uji coba produk akhir atau uji coba kelompok besar dilakukan pada siswa SDN Lumbangrejo 02 dan SDN Pecalukan 01 Prigen Pasuruan dengan melibatkan 30 subyek uji coba.

7. Penyempurnaan produk hasil uji coba lapangan berdasarkan hasil dari uji coba lapangan sesuai dengan langkah ketujuh Gall \& Borg. 
8. Langkah terakhir adalah diseminasi dan implementasi produk yang meliputi menulis laporan dan penyebarluasan produk kepada siswa SDN Lumbangrejo 02 dan SDN Pecalukan 01 Prigen Pasuruan.

Teknik analisis data yang digunakan dalam penelitian pengembangan ini adalah teknik analsis kualitatif dan deskriptif berupa presentase yaitu:

1. Analisis kualitatif digunakan untuk menganalisis hasil pengumpulan data menggunakan model yang digunakan Miles dan Huberman yang dikutip (Sugiyono, 2008) yaitu 1) mereduksi data, 2) penyajian data, 3) kesimpulan awal

2. Analisis deskriptif berupa presentase menggunakan rumus (Sudijono, 2008):

$$
\mathrm{P}=\frac{f}{N} \times 100 \%
$$

Keterangan:

$f$ : Frekuensi yang sedang dicari persentasenya

$\mathrm{N}$ : Number of case (jumlah frekuensi dari banyaknya individu)

$\mathrm{P}:$ Angka persentase

Apabila datanya berupa persentase, proporsi maupun rasio, maka kesimpulan dapat diambil, disesuaikan dengan permasalahannya (Arikunto, 2006). Berikut ini penggolongan persentase kategori yang akan digunakan adalah:

Tabel 1. Kategori Kelayakan

\begin{tabular}{ccc}
\hline Kategori & Persentase & Keterangan \\
\hline Baik & $76 \%-100 \%$ & Digunakan \\
\hline Cukup & $56 \%-75 \%$ & Digunakan \\
\hline Kurang Baik & $40 \%-55 \%$ & Tidak digunakan \\
\hline Tidak baik & Kurang dari $40 \%$ & Tidak digunakan \\
\hline
\end{tabular}

\section{HASIL DAN PEMBAHASAN}

Pada penyajian data analisis kebutuhan yang diberikan kepada 2 guru penjas dan 30 siswa SDN Lumbangrejo 02 dan SDN Pecalukan 01 Prigen 
Pasuruan. Untuk mendapatkan data peneliti menggunakan metode pengumpulan data berupa angket.

Tabel 2. Penyajian Data Hasil Analisis Kebutuhan 2 Guru dan 30 Siswa

\begin{tabular}{|c|c|c|}
\hline No & Kom & Temuan \\
\hline 1 & $\begin{array}{l}\text { Analisis } \\
\text { kebutuhan } \\
\text { guru } \\
\text { melalui } \\
\text { pengisian } \\
\text { angket }\end{array}$ & $\begin{array}{l}\text { 1. diperoleh data bahwa } 50 \% \text { siswa sering } \\
\text { mengalihkan perhatian pada siswa lain saat anda } \\
\text { memberikan materi gerak dasar melompat } \\
\text { 2. diperoleh data bahwa } 100 \% \text { pengembangan model } \\
\text { pembelajaran gerak dasar melompat diperlukan } \\
\text { 3. diperoleh data bahwa } 100 \% \text { setuju dilakukan } \\
\text { pengembangan model pembelajaran gerak dasar } \\
\text { melompat untuk siswa kelas IV melalui permainan } \\
\text { lompat cermin secara sintetik dengan variasi } \\
\text { model-model pembelajaran sehingga kompetensi } \\
\text { yang diharapkan bisa tercapai }\end{array}$ \\
\hline 2 & $\begin{array}{l}\text { Analisis } \\
\text { kebutuhan } \\
\text { siswa } \\
\text { melalui } \\
\text { pengisian } \\
\text { angket }\end{array}$ & $\begin{array}{l}\text { 1. diperoleh data bahwa } 80 \% \text { siswa menyatakan } \\
\text { materi pembelajaran gerak dasar melompat yang } \\
\text { sudah diberikan oleh guru sulit untuk dipahami } \\
\text { 2. diperoleh data bahwa } 93,3 \% \text { siswa menyatakan } \\
\text { materi pembelajaran gerak dasar melompat yang } \\
\text { sudah diberikan oleh guru sulit untuk dipraktekkan } \\
\text { 3. diperoleh data bahwa } 75 \% \text { siswa menyatakan } \\
\text { setuju jika dibuat/dikembangkan model-model } \\
\text { pembelajaran gerak dasar melompat dengan } \\
\text { berbagai variasi guna mempercepat proses } \\
\text { keterampilan gerak dasar melompat }\end{array}$ \\
\hline
\end{tabular}


Tabel 3. Penyajian Data Evaluasi (Ahli) 1 Orang Ahli Pembelajaran, 1 Orang Ahli Pendidikan Jasmani dan 1 Orang Ahli Permainan Lompat Cermin

\section{No Komponen Temuan}

1. Data evaluasi ahli pembelajaran diperoleh

Evaluasi ahli

pembelajaran

oleh Dr. Ahmad

1 Lani, M.Kes

$(n=1)$ dengan

jumlah instrumen

12 pertanyaan hasil $81,25 \%$ maka dapat dinyatakan bahwa model pembelajaran gerak dasar melompat melalui permainan lompat cermin untuk siswa sekolah dasar dapat digunakan dan siap untuk diuji cobakan pada siswa SDN Lumbangrejo 02 dan SDN Pecalukan 01 Prigen Pasuruan

2. Menyusun manual book

1. Data evaluasi ahli pendidikan jasmani diperoleh hasil $91,67 \%$ maka dapat dinyatakan bahwa model pembelajaran

Evaluasi ahli pendidikan jasmani oleh Drs.

2 Sulikan, MS $(\mathrm{n}=1)$ dengan jumlah instrumen

12 pertanyaan gerak dasar melompat melalui permainan lompat cermin untuk siswa sekolah dasar dapat digunakan dan siap untuk diuji cobakan pada siswa SDN Lumbangrejo 02 dan SDN Pecalukan 01 Prigen Pasuruan

2. Sesuaikan model pembelajaran gerak dasar melompat dengan proses pertumbuhan dan perkembangan anak usia dini

3. Model pembelajaran melompat tidak boleh terlalu dipaksakan

\begin{tabular}{lll}
\hline & Evaluasi ahli & 1. Data evaluasi ahli permainan lompat \\
& permainan & cermin diperoleh hasil $87,50 \%$ maka dapat \\
3 & lompat cermin & dinyatakan bahwa model pembelajaran \\
oleh Drs. H. & gerak dasar melompat melalui permainan \\
Budijanto, M.Kes & lompat cermin untuk siswa sekolah dasar \\
& $(n=1)$ dengan & dapat digunakan dan siap untuk diuji \\
\hline
\end{tabular}




\begin{tabular}{ll}
\hline jumlah instrumen & cobakan pada siswa SDN Lumbangrejo 02 \\
12 pertanyaan & dan SDN Pecalukan 01 Prigen Pasuruan \\
2. & Tentukan anak yang menjadi cermin agar \\
& permainan mudah dilakukan \\
3. Perjelas gambar untuk mengetahui batas & dan area bermain
\end{tabular}

Tabel 4. Penyajian Data Hasil Uji Coba

\begin{tabular}{|c|c|c|}
\hline No & Komponen & Temuan \\
\hline 1 & $\begin{array}{l}\text { Uji coba } \\
\text { kelompok kecil } \\
(\mathrm{n}=8) \text { dengan } \\
\text { jumlah } \\
\text { instrumen } 12 \\
\text { pertanyaan }\end{array}$ & $\begin{array}{l}\text { 1. diperoleh data } 69,27 \% \text { maka dapat } \\
\text { dinyatakan bahwa model pembelajaran } \\
\text { gerak dasar melompat melalui permainan } \\
\text { lompat cermin untuk siswa sekolah dasar } \\
\text { dapat digunakan pada siswa SDN } \\
\text { Lumbangrejo } 02 \text { dan SDN Pecalukan } 01 \\
\text { Prigen Pasuruan }\end{array}$ \\
\hline 2 & $\begin{array}{l}\text { Uji coba } \\
\text { kelompok besar } \\
\text { ( } n=30) \text { dengan } \\
\text { jumlah } \\
\text { instrumen } 12 \\
\text { pertanyaan }\end{array}$ & $\begin{array}{l}\text { 1. diperoleh data bahwa } 82,29 \% \text { maka dapat } \\
\text { dinyatakan bahwa model pembelajaran } \\
\text { gerak dasar melompat melalui permainan } \\
\text { lompat cermin untuk siswa sekolah dasar } \\
\text { dapat digunakan pada siswa SDN } \\
\text { Lumbangrejo } 02 \text { dan SDN Pecalukan } 01 \\
\text { Prigen Pasuruan }\end{array}$ \\
\hline
\end{tabular}




\section{Evaluasi Ahli Untuk Model Pembelajaran Gerak Dasar \\ Melompat Melalui Permainan Lompat Cermin untuk Siswa Sekolah Dasar}

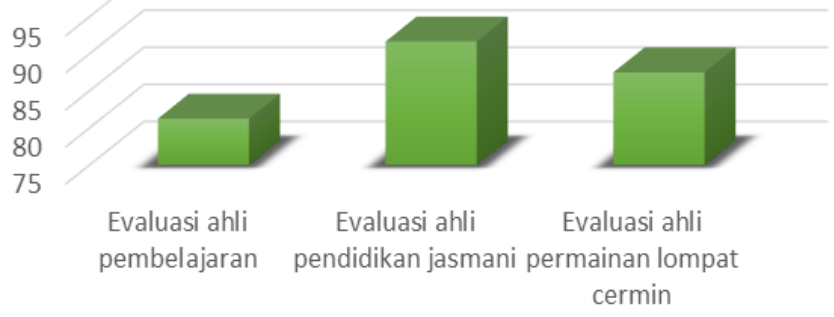

Gambar 1. Evaluasi Ahli Model Pembelajaran Gerak Dasar Melompat Melalui Permainan Lompat Cermin untuk Siswa Sekolah Dasar

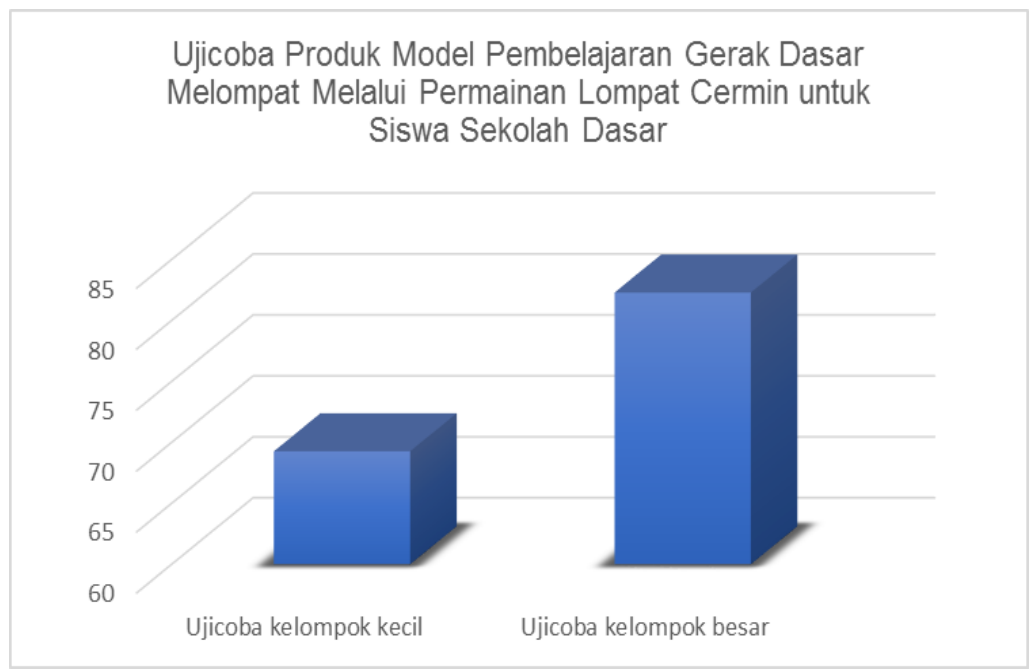

Gambar 2. Uji Coba Produk Model Pembelajaran Gerak Dasar Melompat Melalui Permainan Lompat Cermin untuk Siswa Sekolah Dasar

Berdasarkan data evaluasi ahli dan uji coba pada gambar 2 maka dapat diketahui bahwa model pembelajaran yang dikembangkan sudah memenuhi aspek kesesuaian, kemanfaatan, kemenarikan dan keefektifan untuk diterapkan. Hasil penelitian ini juga mendukung beberapa penelitian lain tentang pengembangan model pembelajaran melompat yang dilakukan oleh beberapa peneliti yaitu permainan level jump dan garis tangkap (Rinanto, 2015), permainan lompat bergandengan (Anggi Feri Setiadi, Rumini, 2015).

Tujuan penelitian yang mengharapkan kemenarikan dan kevariatifan model pembelajaran sudah tercapai jika melihat data yang SPORTIF, 4 (2) 2018 | 145-158 
sudah diperoleh. Model pembelajaran melompat yang selama ini dilakukan relatif sama dengan yang sudah ada sedangkan hasil penelitian ini menunjukkan kebaruan, hal ini bisa dilihat pada keantusiasan anakanak ketika mencoba dan sering terjadinya diskusi antar anak tentang cara bermainnya.

Model permainan lompat cermin area bermain persegi 3 petak

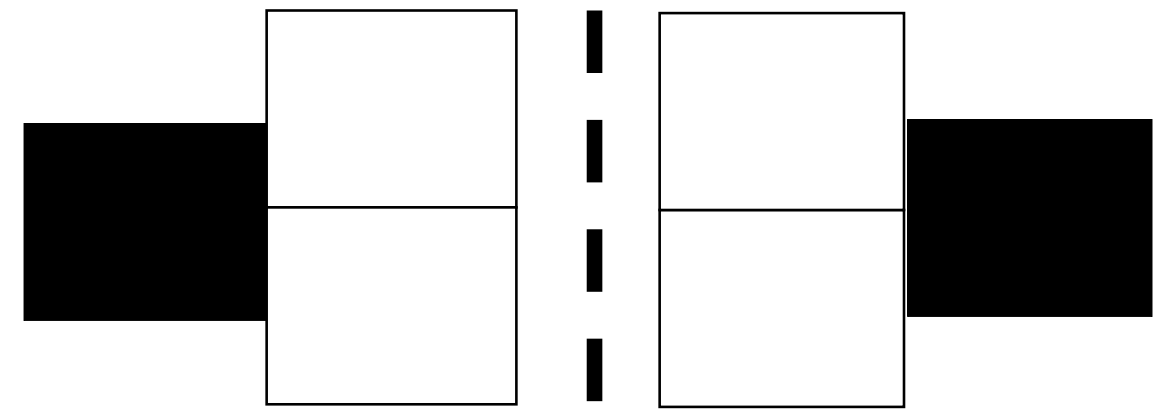

Model permainan lompat cermin area bermain persegi 4 petak
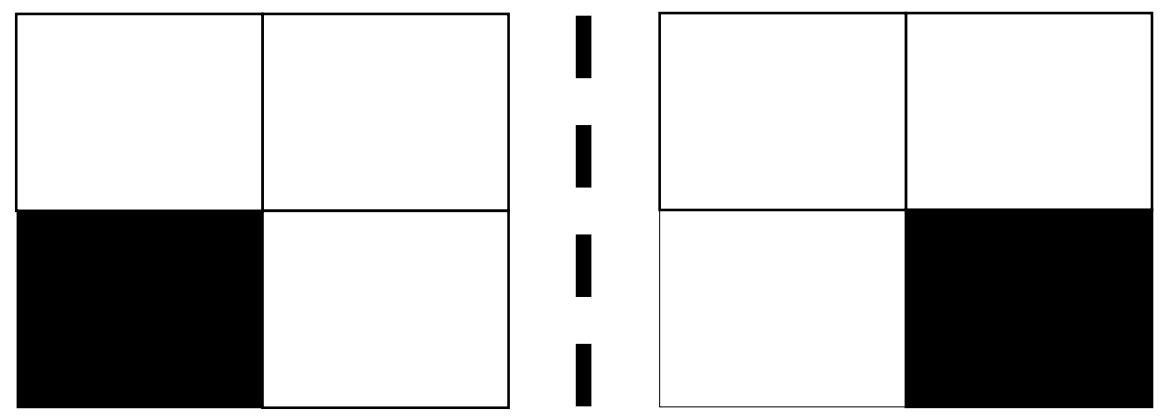

Model permainan lompat cermin area bermain persegi 5 petak
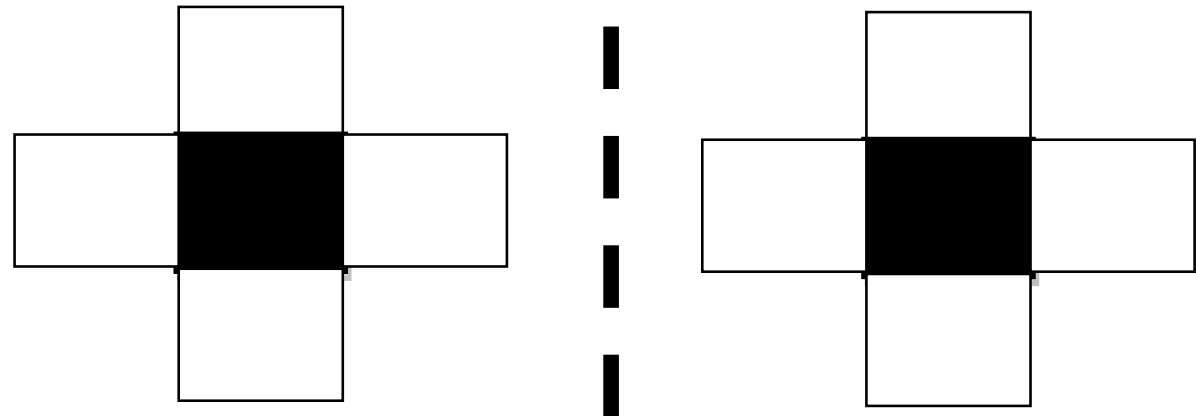

Jumlah pemain : 2 - 4 anak

Alat yang digunakan: kapur, lapangan

Waktu bermain : 1 menit sampai dengan tak terbatas (sesuai kemampuan)

Cara bermain

1. Tentukan pemain yang menjadi cermin 
2. Permainan dimulai dari petak yang berwarna hitam

3. Pemain yang menjadi cermin harus mengikuti kearah mana pemain nyata melompat.

4. Permainan bisa menggunakan 1 kaki atau 2 kaki.

\section{KESIMPULAN DAN SARAN}

Berdasarkan data yang diperoleh dari evaluasi ahli pembelajaran, evaluasi ahli pendidikan jasmani, evaluasi ahli permainan lompat cermin, uji coba kelompok kecil, uji coba kelompok besar maka dapat disimpulkan bahwa model pembelajaran gerak dasar melompat melalui permainan lompat cermin untuk siswa sekolah dasar dapat digunakan dan disebarluaskan. Beberapa saran yang diberikan oleh peneliti sehubungan dengan produk yang dikembangkan yaitu diantaranya 1) produk pengembangan ini sudah dikemas dalam bentuk video sehingga mudah untuk dipelajari karena dapat dijadikan rujukan untuk memberikan materi pembelajaran melompat, 2) sebelum disebarluaskan kesasaran yang lebih luas sebaiknya produk dikaji ulang dan dilakukan penyesuaianpenyesuaian sesuai dengan keadaan sasaran yang dituju agar lebih mudah diterima, 3) melakukan sosialisasi pada pihak-pihak yang terkait untuk memperoleh ijin dan pengakuan sebagai bekal penerapan produk di lapangan.

\section{UCAPAN TERIMA KASIH}

Ucapan Terima kasih kami sampaikan kepada semua pihak yang telah terlibat secara langsung maupun tidak langsung dalam penyelesaian penelitian ini. Terima kasih juga kami sampaikan kepada para ahli yang telah memberikan masukan-masukan demi kesempurnaan dari produk penelitian ini.

\section{DAFTAR PUSTAKA}

Adhanisa, L., Kridalukmana, R., \& Martono, K. T. (2016). Pembuatan Permainan Lompat Karung Berbasis iOS Menggunakan GameSalad. Jurnal Teknologi Dan Sistem Komputer, 4(2), 414-424. 
Ali Khafidin S. (2015). Meningkatkan Hasil Belajar Lompat Jauh Gaya Jongkok Melalui Permainan Jump Box. Journal of Physical Education, Sport, Health and Recreations, 4(8), 1983-1987.

Anggi Feri Setiadi, Rumini, H. W. (2015). Model Pembelajaran Gerak Dasar Melompat Dalam Penjasorkes Melalui Permainan Lompat Bergandeng Pada Siswa Kelas Iv Sekolah Dasar. Journal of Physical Education, Sport, Health and Recreations, 4(5), 1807-1813.

Ardhika, D. F. (2012). Upaya Meningkatkan Hasil Belajar Gerak Dasar Lompat Melalui Modifikasi Permainan Tradisional Engklek Pada Siswa Kelas li Sd Negeri 2 Jeruk Kabupaten Blora Tahun 2013/2014. Journal of Physical Education, Sport, Health and Recreations, 1(2), 648-655.

Ariawan, D. C. (2015). Upaya Meningkatkan Hasil Belajar Lompat Dan Loncat Melalui Permainan Tali Merdeka. Journal of Physical Education, Sport, Health and Recreations, 4(10), 2123-2131.

Arikunto, S. (2006). . Prosedur Penelitian Suatu Pendekatan Praktek Edisi Revisi VI. Jakarta: Rineka Cipta.

Bakhtiar, W. (2010). Pembelajaran Teknik Dasar Lompat Jauh Melalui Permainan Rangkaian 3 Pos Pada Siswa Kelas V Sd Negeri Bumijawa 07 Kecamatan Bumijawa Kabupaten Tegal Tahun 2013. Journal of Physical Education, Sport, Health and Recreations, 21(1), $1-11$.

BOTA, E. (2103). Contribution of the game in the development of motor skills during the physical education class. Timisoara Physical Education and Rehabilitation Journal., 6(11), 65-69.

Burstiando, R., \& Nurkholis, M. (2017). Permainan Invasi dan Permainan Netting untuk Meningkatkan Keterampilan Gerak Dasar Fundamental Siswa SD Negeri Se Kecamatan Mojoroto Kota Kediri. Jurnal SPORTIF : Jurnal Penelitian Pembelajaran, 3(2), 167. https://doi.org/10.29407/js_unpgri.v3i2.11892

Hanief, Y. N., \& Sugito, S. (2015). Membentuk Gerak Dasar Pada Siswa Sekolah Dasar Melalui Permainan Tradisional. Jurnal SPORTIF: Jurnal Penelitian Pembelajaran, 1(1), 100-113. https://doi.org/https://doi.org/10.29407/js_unpgri.v1i1.575

Ilham. (2011). Pengaruh Permainan Tradisional Terhadap Peningkatan Kemampuan Lompat Jauh Tanpa Awalan Siswa Sekolah Dasar Negeri No. 52/lv Kota Jambi. Jurnal Penelitian Universitas Jambi Seri Humaniora, 13(2), 19-24.

Kisyanto, D. (2015). Upaya Meningkatkan Hasil Belajar Lompat Jauh Gaya Jongkok Menggunakan Permainan Lompat Pada Siswa Kelas V Mi Nurul Iman Kendalserut Kecamatan Pangkah Kabupaten Tegal 
Tahun Pelajaran 2013/2014. Journal of Physical Education, Sport, Health and Recreations, 4(10), 2117-2122.

Ljubojevi, M., Muratovi, A., \& Bubanja, M. (2016). Effects of Various Physical Education Curriculum on Motor Skills in Students of Final Grades in Primary School. Sport Mont, 14, 25-28.

Pramono, T. E., Setyawati, H., \& Akhiruyanto, A. (2015). Peningkatan Hasil Belajar Lompat Tinggi Menggunakan Modifikas Permainan Lompat Karet Pada Siswa Tunarungu Di Sdlb Negeri Semarang Tahun Ajaran 2013/2014. Journal of Physical Education, Sport, Health and Recreations, 4(3), 1660-1665.

Raharjo, T. B. (2015). Meningkatkan Hasil Belajar Lompat Jauh Melalui Permainan Lompat Gelang-Gelang Pada Siswa Kelas V Sdn 02 Garungwiyoro. Journal of Physical Education, Sport, Health and Recreations, 4(8), 2002-2009.

Ramadan, H. T. dan G. (2018). Pengembangan Model latihan Keseimbangan Untuk Sekolah Dasar. Jurnal SPORTIF: Jurnal Penelitian Pembelajaran, 4, 134-144.

Rinanto. (2015). Pengembangan Model Pembelajaran Lompat Jauh Gaya Jongkok Melalui Permainan Level Jump Dan Garis Tangkap Pada Siswa Kelas Vii Smp Negeri 1 Tulis Kecamatan Tulis Kabupaten Batang Tahun 2013. Journal of Physical Education, Sport, Health and Recreations, 4(6), 1839-1844.

Stanojević, I. (20116). Influence Of Programmed Exercise On The Motor Abilities Of Preschool Children. International Journal of Cognitive Research in Science, Engineering and Education, 4(1), 55-58.

Sudijono, A. (2008). Pengantar Statistik Pendidikan. Jakarta: Grafindo Persada.

Sugiyono. (2008). Metode Penelitian Kuantitatif, Kualitatif dan R\&D. Bandung: Alfabeta.

Suroso, A., Rustiana, E. R., \& Sugiharto, S. (2013). Pengaruh Model Pembelajaran Dan Motorik Dasar Sekolah Dasar Kelas Awal. Journal Of Physical Educatin And Sport, 2(1), 187-192.

Suroso, M. B. (2015). Permainan Lompat Kanguru Untuk Meningkatkan Hasil Belajar Lompat Jauh Gaya Jongkok. Journal of Physical Education, Sport, Health and Recreations, 4(9), 2089-2093. 